\title{
172 LittéRéalité
}

Bien que François Paré n'hésite pas à souligner les immenses difficultés que doivent affronter les littératures exiguës, l'auteur entrevoit néanmoins la possibilité d'une revalorisation. Face au déclin évident du discours intellectuel dominant, il est de plus en plus permis d'envisager « l'avènement d'une vision renouvelée du savoir " (p. 78). L'affaiblissment d'une institution littéraire tyrannisée par le culte du Même ouvrirait donc l'espace culturel à une hétérogénéité de discours privilégiant la différence et le pluriel.

La forme fragmentaire à "vignettes " discontinues de ce livre important séduit tout autant que la pensée subtile et le sentiment d'urgence qui s'en dégagent. Les littératures de l'exiguité est un beau texte dont le sujet est d'actualité, ce qui mérite qu'on s'y attarde.

David Walker

Université York

\section{Lélia Young. Entre l'outil et la matière. Textes poétiques. Illustrations de l'auteure.}

Toronto : Éditions du GREF, Collection Écrits Torontois, 1993. 144 p.

Ce premier recueil de Lélia Young, savamment divisé en cinq parties plus ou moins égales, est composé de poèmes pour la plupart titrés. Illustrés par l'auteure et exécutés à l'ordinateur, les dessins réussissent parfois à traduire l'intention de certains textes poétiques, et parfois ils s'en décalent pour créer des effets de contrastes ou d'adhésions, d'oppositions ou d'ajustements. Trois poèmes liminaires introduisent le recueil. Le premier reprend en écho celui de Paul Éluard, "J'écris ton nom. » Lélia Young intitule son poème, "J'écris ces mots » afin de plaider l'espérance, la justice, la liberté de la femme, et l'annulation de toute souffrance. Le deuxième poème porte bien son titre, "Paix, " car cette paix recherchée donne le ton à l'ensemble du recueil. C'est elle qui nous permet d'atteindre l'extase et l'éternité.

Dans la première partie, "Éclipse, " l'auteure aborde certaines thématiques de la terre et de la mer, du soleil et des océans, et trace ainsi 
un portrait des saisons de son adolescence. La magie des mots et les murmures $d$ 'une vérité première traduisent la verve et l'élan de la jeunesse. C'est « Le halo de l'éveil » dont le regard essentiel et lucide mesure la fragilité des êtres et des choses. Le flottement et l'énergie de toute naissance se dessine ainsi à l'horizon. La vision du poète esquisse "L'inconnu familier, " son rythme et ses mystères, ses interrogations lancinantes et ses réponses belliqueuses. La fonction du poète revient ici à nommer le désir, la tristesse, et la joie. Ébauches et esquisses, portraits et éclipses assument le manque et l'angoisse, la frayeur et le miroitement des jours heureux.

Dans la seconde partie, "La femme phénix, " c'est l'essor de l'imagination poétique, et le devenir de l'être. « Le corps porteur » du texte cherche la vérité dans « une parole indicible/réconfort des fusions/ incertaines » (49). On peut dire que la poésie de Lélia Young est essentiellement fusionnelle, car elle se rebelle contre les injustices et les avatars de l'histoire. Elle tente de retrouver l'équilibre précaire de la fusion du sensible et de l'intelligible. Ainsi : « la femme phénix regarde/sortie des branches ornementales/elle façonne les alvéoles de sa ruche/à courte échéance » (57). Cette définition cadre bien avec les thématiques de la troisième partie intitulée « Les survivants de l'inouï. » Ici, nous assistons à la croissance spirituelle vers la sagesse et corporelle vers le déchiffrement du temple individuel, social et mystique. Comme elle le dit si bien dans son poème sur l'attente, en tant qu'expectative « le parcours tire/au rêve $d^{\prime}$ une odyssée " (65). De la grotte à l'errance, les bourgeons de la lumière atteignent parfois certains carrefours à grandes ouvertures. Ce sont les dédales mythiques et religieux, les éléments terrestres et célestes. Et les lecteurs suivent le fil d'Ariane pour occulter l'oubli de tant d'impuissance et d'injustice. " Le rappel du blé » traite du mirage de la foi, mais aussi de la tyrannie et de la liberté de l'arbitraire et des mots qui le prennent en charge.

Dans la quatrième partie, "Terracotta, » Lélia Young fait un retour fructueux aux sources de son inspiration poétique, la Méditerranée, et particulièrement Carthage et la Tunisie, et le Canada, particulièrement Montréal. Le poète retrouve les jours heureux de son adolescence, chante 
la fidélité et l'union, une musique « unifiante. " L'art visuel et ses couleurs, la danse et ses gestuelles dessinent des paysages intérieurs, les saisons printanières et les fontaines des rêves. Ici,

les différences se taisent

dans le crépissement

d'un solomatinal

Proche de la terre

l'argile se fait tendre

et le parfum s'évapore

d'une anse veloutée

Dans une auréole brunâtre

danse l'informulable

malléabilité (103).

L'imagerie chez Lélia Young est souvent condensée en une constatation lumineuse, exprimée sous forme plus ou moins abstraite : « En flottant l'image captive/fascine jusqu'au rappel » (110).

Dans la cinquième partie, "Scripto-mitose " (sonorité pas très heureuse), Lélia Young réfléchit sur l'acte d'écriture. Le suffixe « ose » (du grec osis) implique un état anormal ou maladif. Mais cette associatoin au biologique traduit bien l'intention de l'auteure, qui fait l'équivalence entre la création, l'acte d'aimer et le processus de la division cellulaire. En plus de relier le titre à la nature biologique du poème, elle transforme cet acte, littéral et métaphorique, en perpétuel questionnement pour arriver à la transparence et nous sortir de la solitude. Le poète nous dit « [ $d$ ']oublier un peu la poésie » et de «Vivre dans les yeux du poète » (122), intention louable mais qui ne correspond pas à cette soif fusionnnelle qu'elle voudrait accomplir par l'intermédiaire de son texte poétique. Lélia Young tente de se convaincre de cette mystique de la créativité : "J'ai besoin de croire/pour trouver mon langage/ $\mathrm{m}^{\prime}$ envelopper de soir/dans ma robe de jour. »

En somme, la poésie est vraiment libératrice et pacifiante. Elle sonne le rappel à plus de justice et d'unité entre les humains, mais aussi entre les êtres et les éléments naturels, l'environnement et le social. Ainsi, la 
poésie de Lélia Young relève le défi qui rythme notre existence. Techniquement, ces poèmes sans ponctuation, présentés parfois d'une façon éclatée, traduisent cette recherche logique et fondamentale de la sortie des ténèbres vers la lumière de la renaissance. À ce titre, ce recueil établit un jalon important dans la carrière du poète et doit retenir l'attention des lecteurs.

Hédi Bouraoui

Université York

\section{Louis et Marie Francœur: Grimoire de l'art grammaire de l'être. Québec/Paris : Presses de l’Université Laval/Klincksieck. 1993. 376 p.}

Un volumineux ouvrage abordant des problèmes de grammaire textuelle (ou de "sémiotique » au sens français) dans une optique mistructurale, mi-herméneutique, et se réclamant d'une volonté (affirmée sinon réalisée) de démystification de l'œuvre littéraire :

Pour plusieurs lecteurs, l'œuvre d'art littéraire n'apparaitelle pas encore, à l'exemple de ce qu'était la grammaire latine pour l'homme du peuple médiéval, un véritable grimoire, objet inintelligible, obscur, dont l'impossible déchiffrement le transforme en un signe magique et mystérieux ? Nous croyons en la possibilité de démystifier cette pensée trop répandue, pour peu que nous disposions $d^{\prime} u n$ art de lire que nous puiserions dans une authentique grammaire de l'art (p. 1).

L'exposé se subdivise en deux grandes parties : une « SÉMIOTIQUE » (deux chapitres) et une «SÉMIOSIS » (cinq chapitres). Deux courts textes sont placés en annexe : un extrait du recueil $L^{\prime} A b a t i s$ de Félix-Antoine Savard et le texte intégral du manifeste Refus global de Paul-Émile Borduas et alii. La bibliographie (dix pages) est subdivisée en une liste des " œuvres littéraires citées » et une « bibliographie critique » des ouvrages et articles de référence. 